\title{
A REVIEW OF HELICOBACTER PYLORI INFECTION DISEASES, ANTIBIOTIC RESISTANCE AND DIAGNOSIS
}

\author{
BOLAI PAUL ${ }^{1 *}$, SENTHIL ADIMOOLAM ${ }^{1}$, MOHD JAVED QURESHI ${ }^{1}$, NAHLAH ELKUDSSIAH ISMAIL ${ }^{2}$
}

${ }^{1}$ Department of Dosage Form Design, Faculty of Pharmacy, MAHSA University, Selangor, Malaysia. ${ }^{2}$ Department of Clinical Pharmacy, Faculty of Pharmacy, MAHSA University, Selangor, Malaysia. Email: bolai0199@gmail.com

Received: 12 January 2018, Revised and Accepted: 22 June 2018

\section{ABSTRACT}

Objective: The aim of the study was designed to assess the mechanisms of antibiotic resistance in Helicobacter pylori, affecting disease by this infection and diagnostic methods which are used to detect H. pylori.

Methods: A wide literature search was performed using PubMed, Medline, Cinahl, Embase, Educational Resources Information Center, PsycINFO, Google Scholar, Scopus, and Web of Science, and review of appropriate epidemiologic studies conducted from 1995 to 2017 for studies fully published investigating a contribution between H. pylori infection, antibiotic resistance, and diagnosis of H. pylori infection.

Results: H. pylori infection is extremely contributed to the main symptoms and death that is currently affecting $50-75 \%$ of the people in the world. It is more affected in developing countries compared to developed countries. These infections are regarded to be the most important reasons for gastric cancer, peptic ulcer, chronic gastritis, duodenal ulcer, mucosa-associated lymphoid tissue lymphomas, and gastric adenocarcinoma. About $90-100 \%$ of duodenal ulcers and $60-90 \%$ of gastric ulcers were associated with $H$. pylori infections. At present, antibiotic resistance is a growing problem for the eradication of $H$. pylori infection; it contains metronidazole, amoxicillin, clarithromycin, and levofloxacin resistance. Diagnosis of $H$. pylori infection is a crucial part for the better treatment of those diseases. Different types of testing method for $H$. pylori infection are used including invasive (endoscopic image, histology, rapid urease test, and culture) and non-invasive (urea breath test, stool antigen test, and serological).

Conclusion: H. pylori antibiotic resistance is the major contributor to the failure of H. pylori treatment. Appropriate diagnostic method selected in detecting H. pylori antibiotic resistance may lead to reduced treatment failures and less antibiotic resistance.

Keywords: Helicobacter pylori, Gastric cancer, Peptic ulcer, Antibiotic resistance, Invasive test, Non-invasive test.

(C) 2018 The Authors. Published by Innovare Academic Sciences Pvt Ltd. This is an open access article under the CC BY license (http://creativecommons. org/licenses/by/4. 0/) DOI: http://dx.doi.org/10.22159/ajpcr.2018.v11i12.24745

\section{INTRODUCTION}

Helicobacter pylori is a Gram-negative bacterium which is found in the mucus layer and the mucosa of the stomach, and it is regarded to be associated with stomach diseases such as chronic gastritis, gastric ulcers, duodenal ulcers, and gastric cancer [1-4]. It has been recently found that over $90 \%$ of duodenal ulcers and $50-70 \%$ of benign gastric ulcer are associated with $H$. pylori infection. It has been recently found that over $90 \%$ of duodenal ulcers and $50-70 \%$ of benign gastric ulcers are associated with $\mathrm{H}$. pylori infection [5,6]. This infection could be regarded as one of most universal infectious agent where is exist to determine diverse disease [7]. It is also spread in worldwide and affecting different types of factors such as environmental factors, virulence factors, and host factors, which caused by gastric cancer, chronic gastritis, and peptic ulcer diseases (PUD) (Fig. 1) [8].

H. pylori is associated with different diseases such as gastritis, PU disease of the stomach and duodenum, gastric adenocarcinoma, and low-grade gastric lymphoma growing from mucosa-associated lymphoid tissue (MALT) $[9,10]$. It is approximately $50 \%-75 \%$ affected with respective infection globally, whereby in the developing countries $70 \%$ of people are affected, whereas the percentage little lowers, $25-50 \%$ in the developed countries [11,12]. Present studies have demonstrated that H. pylori infection is also associated in chronic bacterial infection worldwide, which is affected almost $50 \%$ of people in the developed countries and about $90 \%$ of people in developing countries [13]. The prevalence of H. pylori infection is almost $50 \%$ in the worldwide and this infection is highly affected in developing countries (80-90\%), as well as, the annual incidence of $H$. pylori infection is influenced in developing countries (4-15\%) than industrialized countries $(0.5 \%)[14,15]$. Present studies revealed that $H$. pylori infection is associated with cardiovascular diseases and atherosclerosis [16].
A study demonstrated that $H$. pylori is infected in human gastric mucosa of more than $50 \%$ of people in the world which is caused by long-term colonization and inflammation as a produce to a verity of diseases, from gastritis to PU (gastric ulcer and duodenal ulcer), gastric cancer, and the MALT lymphoma [17]. This infection is existed in beneath the gastric mucous layer, nearby to the gastric epithelial cells [18]. A work reported that H. pylori seropositivity is a risk issue for gastric, colorectal, pancreas, and hepatobiliary cancers and an improved seroprevalence rate was also found in different respiratory ailment such as chronic bronchitis, asthma, and pulmonary tuberculosis [19].

Nowadays, antibiotic resistance is an international healthiness problem which is major cause of treatment failures in $H$. pylori infection. Prevalence of $H$. pylori antibiotic resistance is not the same in all over the world because it depends on geographical variations [20]. It is increased in worldwide, and most of drugs are resistance for the eradication of $H$. pylori infection such as metronidazole (MTZ), clarithromycin (CLA), and amoxicillin (AMX) due to decreased efficacy of drug [21]. Eradication of $H$. pylori infection failure is main reason of one or more two antibiotic resistances and genetic alteration and biofilm formation that is associated with $H$. pylori infection $[22,23]$. At present, H. pylori infection is complicated to eradicate as failure rate exist $10-40 \%$ due to increasing resistance of the microbe to conventional antimicrobial agents [24]. Therefore, improving antibiotic resistance rates and lower eradication rates are the main troubles in $H$. pylori infections treatment.

Diagnosis of $H$. pylori infection is a crucial part of the better treatment of many gastroduodenal diseases [25]. There are two types of a diagnostic test such as invasive and non-invasive diagnostic test that is used for detection of $H$. pylori infection. Invasive diagnostic tests are involved 


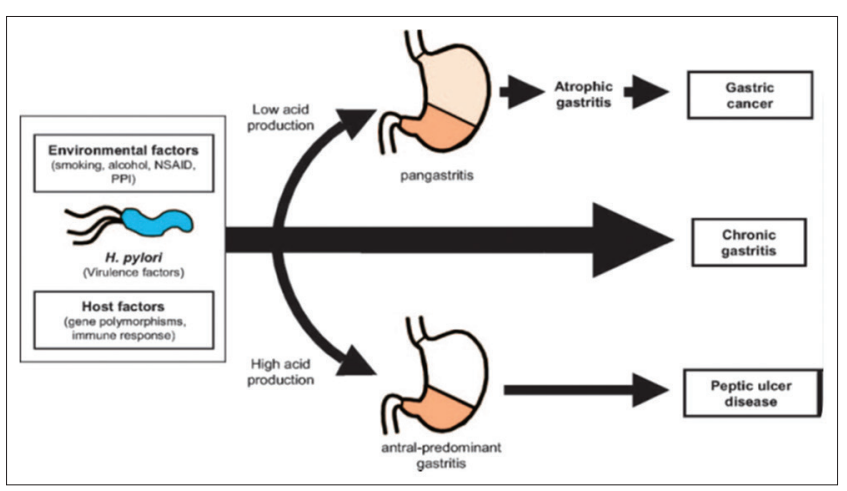

Fig. 1: Schematic representation of the factors associated to gastric pathology and Helicobacter pylori infection diseases [8]

in an endoscopic image, histology, rapid urease test, culture, and molecular methods, as well as non-invasive diagnostic tests, including urea breath test (UBT), stool antigen test, serological, and molecular examinations [26]. It has proved that for primary diagnosis of $H$. pylori infection, rapid urease test, and tissue staining with gastric tissues attained by endoscopy of the upper gastrointestinal tract is necessary to confirm H. pylori infection in both adults and children [27]. Therefore, this study major purposed to provide a cause of antimicrobial resistance in $H$. pylori infection, disease and which methods are best for H. pylori infection test.

\section{METHODS}

During the primary search, different medical terms and phrases related to $H$. pylori infection, diseases, epidemiology, antibiotic resistance, and diagnosis of $H$. pylori infection were singling or in various combinations searched from various databases including PubMed, Medline, Cinahl, Embase, Educational Resources Information Center, Google Scholar, PsycINFO, Scopus, and Web of Science, to identify articles containing related information on the topic of study. All relevant articles published between 1995 and 2017 were identified and selected for further review.

\section{Data analysis and results}

A total of 1045 related articles were identified through electronic search, while 10 were through manual methods, and preliminary screening of the articles revealed that 431 were duplicates, hence excluded from further analysis.

The titles of selected articles and abstracts were again checked for relevancy, and 47 were eligible for full-text screening, after which 10 of the publications qualified for the last stage of the selection process, as shown in Fig. 2.

Details descriptions of the papers were then carried out based on the following criteria: (1) Reported by gastric cancer and PU; (2) investigation of the diagnostic methods such as invasive (endoscopic image, histology, rapid urease test, and culture) and non-invasive (UBT, stool antigen test, and serological); and (3) antibiotic resistance such as MTZ, AMX, CLA, and levofloxacin resistance.

\section{Epidemiology of $\boldsymbol{H}$. pylori infection}

H. pylori is one of the general bacterial pathogens in humans which consist of small, curved, highly motile, and remains as colonies in the mucus layer of the human stomach (Fig. 3). It is continuing existent in the stomach which is occurred early in the childhood [28-30]. In developing countries, this infection is rapidly increased and started from first 5 years in life after that persistently exist in life. This infection is transmitted from person to person through oral-oral or fecal-oral routes during childhood in the past decades [31]. A study demonstrated that $H$. pylori is a helical or curved bacillus that colonizes the gastric mucosa and also transmitted in nonculturable coccoid [32]. It was first exposed and acknowledged in 1984 by Marshall and Warren, where it

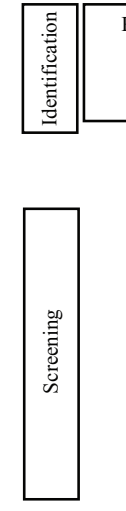

Record identified through database searching $\mathrm{N}=1045$
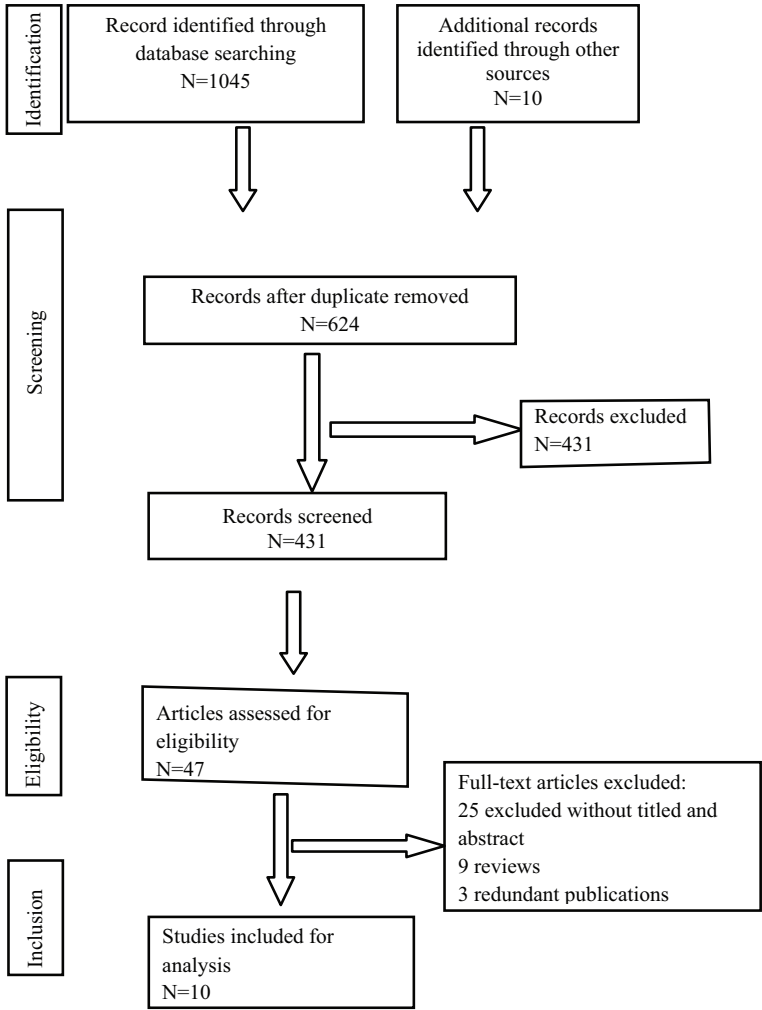

Fig. 2: Flow of information through the different phases of selection of the studies

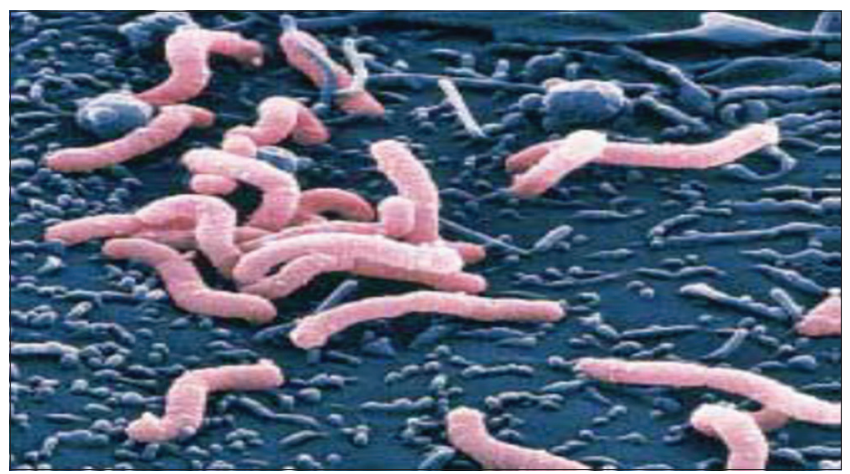

Fig. 3: Colored scanning electron micrograph of Helicobacter pylori on surface [35]

was found in gastric mucosa [33,34]. Recent studies revealed that this infection is prevalent in men rural area, low socioeconomic standard, low educational levels, and crowded places. It was reported that the incidence in Egypt was approximately $50 \%$ in children $\leq 3$ years old and $90 \%$ in adults [35].

\section{Gastric cancer}

H. pylori is the most crucial etiologic aspect for gastric cancer which affected about $50 \%$ of people, and people's deaths are more than $720,000 /$ year globally [36]. It is usually infected malignancies or carcinoma worldwide which is mainly colonized in the human stomach coexisted in about 60,000 years age [37]. Gastric cancer with H. pylori infection is more prevalent in developing countries than in developed countries [38]. It is a major global health warning and the third leading cause of cancer death worldwide, caused by $H$. pylori infection, the Gram-negative, and microaerophilic bacterium [39,40].

Recently, the prevalence rate of gastric cancer is higher in male than female. Some researchers believed that the low occurrence of $H$. pylori 
infection consequence of low incidence of gastric cancer, but geographic variation in gastric cancer prevalence rates cannot be similar describe in $H$. pylori prevalence. For instance, high populations of Africa and India have a higher prevalence rate of $H$. pylori infection but a lower incidence of gastric cancer [41]. Most researchers suggested that the pathogenesis of human gastric cancer is a multi-factorial and multistage method and is associated with cytokine gene polymorphisms which are progress gastric cancer with $H$. pylori (Fig. 4) [42]. In recent studies exposed that gastric cancer is the fourth largest part of malignancy in the earth that is attributed to $63 \%$ gastric cancer [7].

\section{PU disease (PUD)}

PUD is a common illness which is associated with $H$. pylori infection and lifespan incidence rate of approximately $10 \%$. The prevalence rate of $H$. pylori infection with PUD is range from 58\% to $78 \%$ for aged patients, as well as $H$. pylori with a duodenal ulcer is present in $90-100 \%$ of patients, and for gastric ulcer is represent $60 \%-90 \%$ of patients [43]. Recently, studies have shown that $90 \%$ of patients with PUD are infected with this infection [44]. It is found that gastric ulcers distributed within the lesser curvature, in particular along with the transitional zone between corpus and antrum, while duodenal ulcers generally appeared in the duodenal bulb [7]. On the other hands, gastric cancer is increased when people are administered NSAID drugs, while duodenal ulcer is increased when improving acid secretion in the stomach [45]. Currently reported that PU is consists of gastric and duodenal ulcers which are called mucosal defects. On the other hands, in Western countries, duodenal ulcers are four-fold, and it is going on between 20 and 50 years of period, while gastric ulcers are mainly happened in $>40$ years old [29]. Present studies have shown that PU is generally caused by stomach acid and digestive enzyme pepsin that is defects in gastric or duodenal mucosa because of imbalance between acid amount and mucus defense which results in damage of lining in the stomach [46].

\section{MTZ resistance}

MTZ is a 5-nitroimidazole antibiotic that is used for the treatment of H. pylori infection and other infection such as parasitic infections, anaerobic, and microaerophilic bacterial infections. MTZ resistance

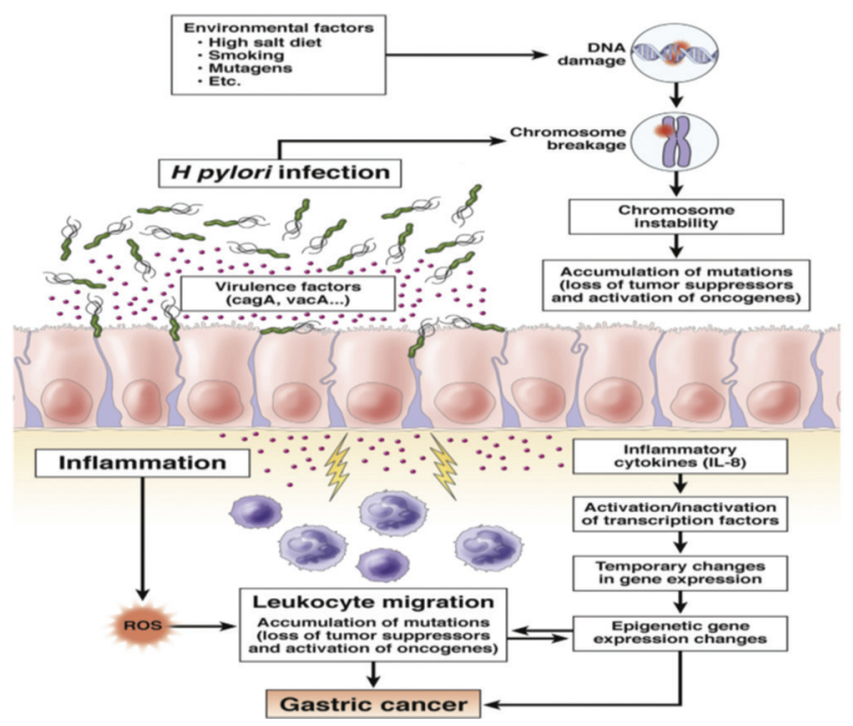

Fig. 4: Interactions between inflammation, bacteria, and the epithelium result in gastric cancer. It shows that the interaction of $H$. pylori, environmental factors, and inflammation in the pathogenesis of gastric cancer; which significant roles leading to progressive chromosome instability. H. pylori-induced inflammation leads to high gastric endothelial cell turnover and a microenvironment that is high in reactive oxygen and nitrogen species, improving opportunities for DNA damage and somatic mutations. IL: Interleukin, ROS: Reactive oxygen species [39] with H. pylori is more affected in developing countries than in developed countries. It is associated with null mutation ferredoxin $(f d x A)$ that is contributed in resistance to MTZ due to amino acid substitution mutations [20]. Null mutations in MTZ-resistance isolated by W (209) $\mathrm{R}$ substitution by polymerase chain reaction (PCR) amplification of $r d x A$ and $R N D$ family of efflux pumps $[47,48]$. It has been reported that mutations are stopped codons or substitutions inactivate the rdxA gene, as a result, the frxA gene improves resistance and represents mutations with rdxA [49].

\section{AMX resistance}

AMX is a broadspectrum and $\beta$-lactams antibiotics. It's binding site penicillin-binding proteins (PBP) in the bacterial cell wall and inhibits cell division; which is observed in E. coli spp and Salmonella spp. [20]. It has demonstrated that antibiotic resistance is a major cause of alterations in PBP and decreased membrane permeability of antibiotics into the bacterial cell; and mutations PBP1A, PBP2, hefC, hopC, and hof $\mathrm{H}$ gene have been contributed to $H$. pylori-resistant strains [50].

\section{CLA resistance}

CLA (6-0-methyl erythromycin) (CLA) is a macrolide antibiotic which is binding to peptidyl transferase loop of domain $\mathrm{V}$ the $23 \mathrm{~S}$ rRNA molecule in ribosomes and blocking bacterial protein synthesis $[22,51]$. It is contributed with A-to-G transition at position 2142 (A2142G) or 2143 (A2143G). PCR method is used to investigate in 23S rRNA gene mutations in CLA-resistant H. pylori, as well as showed that A2142C mutation is lower than A2143G mutation [52]. It is also found that other mutations such as A2115G, G2141A, C2147G, T2190C, C2195T, A2223G, and C2694A could lead to being improving CLA resistance [50]. It has proposed that those all mutations are decreased in the binding site of the drug result in CLA resistance [53].

\section{Tetracycline resistance}

Tetracycline is an antibiotic that is combined in aminoacyl-tRNA to the ribosomal acceptor (A) and blocking bacterial protein synthesis, and antibiotic resistance is associated with mutations in $16 \mathrm{~S}$ rRNA-encoding genes which are detected by PCR method [7]. Antibiotic resistance to tetracycline is the main reason improved energy-dependent efflux of tetracycline that decreases the intracellular concentration of tetracycline and mediated ribosomal protection proteins. It has been also reported that mechanism of antibiotics resistance is declining the affinity of ribosomes for tetracycline, enzymatic inactivation of tetracycline, and point mutations in the 16S rRNA genes which is influencing the binding site of tetracycline [50].

\section{Levofloxacin resistance}

Mechanism of levofloxacin resistance is one kind of gyrA mutation gene which is connected to DNA gyrase code and macrolides. GyrA mutation gene prevents the inhibition of chromosome replication of the bacterium when observed in the presence of drug $[50,53]$.

\section{Endoscopic invasive test for $\boldsymbol{H}$. pylori}

The endoscopic test is associated with identifying H. pylori-associated diseases, such as PUD, atrophic gastritis, MALT lymphoma, and gastric cancer. It is also used to achieve specimen biopsy from gastric mucosa. Antrum and the corpus is favorable biopsy site for $H$. pylori infection in most situations, but corpus biopsy is higher biopsy for patients with antral atrophy or intestinal metaplasia to remove false negative results [26]. Recently, studies have shown that maximum gastric mucous is redness and mucosal swelling, and it is not specifically used detection of $H$. pylori infection due to provide limited value in endoscopy diagnosis [54]. It has been revealed that endoscopy test is improving the diagnostic process for gastric mucosa; whereas it might be timeconsuming and not provide better results than other invasive tests [55].

\section{Histology invasive test}

Histology is the first standard method used for the detection of H. pylori infection [26]. In the presence of representative bacteria between with the inflammatory reaction in the tissue, slides are measured as a diagnostic test for $H$. pylori infection. Studies reported that 
different types of stains are used for detection of $H$. pylori infection such as Giemsa, Acridine O, Warthin Starry, Hp silver stain, Dieterle, Giminez, and McMullen. The hematoxylin and eosin stain used to detect inflammation with bacteria. Giemsa stain is more reasonable in detecting $H$. pylori because it is simple, high sensitivity, and less expensive [56]. Some studies have reported that this test is used to determine histological chronic or chronic active inflammation (gastritis), atrophy, and intestinal metaplasia, but the major problem is high observer-dependency, relatively long waiting time for result, the requirement of specialized skills for performance and relatively high cost for this test [45].

Recent studies demonstrated that it provides critical information related to mucosa such as severity of inflammation, intestinal metaplasia, glandular atrophy, dysplasia, and neoplasia as well as collected antrum and corpus biopsies which indicates sampling from 5 biopsy sites. Corpus biopsy attained from the smaller curvature of the corpus about $4 \mathrm{~cm}$ proximal such as angulus and antrum (both within $2-3 \mathrm{~cm}$ of the pylorus); and greater curvature of the corpus approximately $8 \mathrm{~cm}$ such as cardia and incisura angularis [57].

Fluorescent in situ hybridization is a new manner for histology invasive test that is accepted detection of a specific bacterial factor such as CLA resistance. This method is used to protein-labeled oligonucleotide probes that target a specific gene such as $16 \mathrm{~S}$ and $23 \mathrm{~S}$ ribosomal RNA genes, but this method is laborious, expensive, and not used in clinical practice. It is revealed that the histology test is provided in the historical record and evaluated in gastritis, atrophy, and incisura metaplasia (Fig. 5) [45].

\section{Rapid urease test (RUT) invasive test}

At present, rapid urease test is mostly used in the identification of H. pylori infection due to low-cost, rapid, easy to complete, extremely precise, and widely existing [26]. Current studies have shown that in this infection, urease enzyme converted to urea to release $\mathrm{CO}_{2}$ and $\mathrm{NH}_{2}$. Detection of urease production has been used as a surrogate marker for the detection of the bacterium in antral biopsies and the presence of H. pylori in biopsy specimen converts the urea test reagent to ammonia, as a result, increase in the $\mathrm{pH}$ and a color changes on the $\mathrm{pH}$ indicator. The RUT sensitivity influenced the number of bacteria in the biopsy and presence of blood; at least 10000 cells are needed for a positive result [57]. Also known as campylobacter-like organism test, this test has good sensitivity $(80-100 \%)$ and specificity $(97-99 \%)$ in diagnosing H. pylori (Fig. 6) $[17,56,58]$. Studies have showed that this test, however, cannot be used to assess gastritis [45].

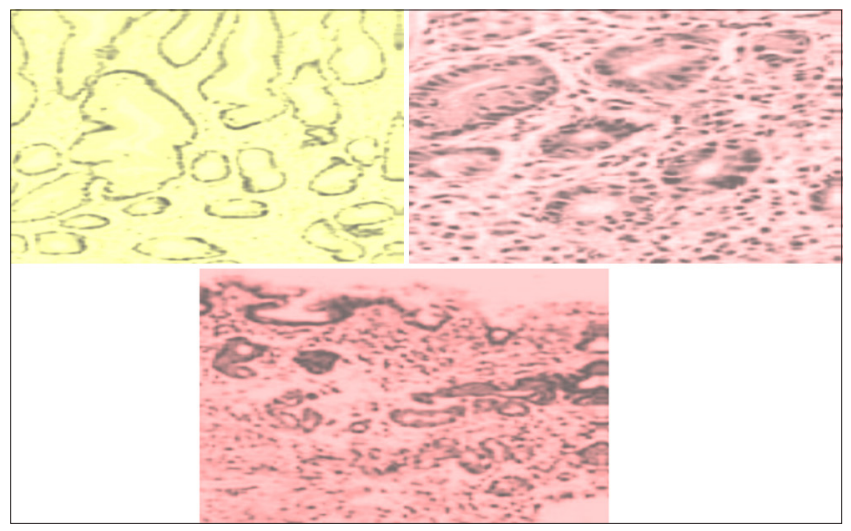

Fig. 5: Histology of gastric mucosa. Top left: Normal antral mucosa, with sparse, infiltrate of lymphocytes in lamina propria. Top right: Active gastritis with neutrophils infiltrating epithelium and marked infiltrate of lymphocytes in lamina propria. Bottom: Atrophy of antral mucosa with loss of specialized glands near muscularis mucosa [45]
Culture invasive test

The culture test is a gold standard method for detection of H. pylori infection, but this test is difficult to perform due to costly, timeconsuming and needs for special media. It is used to recognize the antibiotic susceptibility of $H$. pylori in clinical practice [5].

\section{PCR}

PCR is a molecular method which is used to investigate amplifies a fragment of a gene specific for the $H$. pylori, for example, vacA and cagA gene sequences, 16SrNA, 23SrRNA, DNA gyrase, bacterial genotypes, study pattern of antibiotic resistance, and H. pylori transmission [45]. Recently, studies have demonstrated that the PCR can be performed on stool and tissue specimen and assists identify genes related to antibiotic resistance and virulence [59]. Studies have reported that PCR is used to detect bacterium, pathogenic genes, and specific mutations contributed with antimicrobial resistance [60]. It has also found that PCR method is used to detect of $H$. pylori infection and recognize the exact mutations in the 23S rRNA sequence that provides resistance to CLA [61].

\section{Urea breath noninvasive test}

The UBT is extremely believable for detection of $H$. pylori but for young children the test is more complicated; whereas Canadian consensus guidelines regarded ${ }^{13} \mathrm{C}$-UBT to be the most excellent noninvasive test for the detection of $H$. pylori infection in children [45]. Studies have shown that UBT is the best option for $H$. pylori infection treatment which is completed eradication therapy after four to 6 weeks, but for these test proton pump inhibitors administration must be stopped before 2 weeks [62]. This method is used for hydrolysis of urea by H. pylori to produce carbon dioxide and ammonia which are used to detect in breath samples, representing the presence of active $H$. pylori infection. UBT has a sensitivity and specificity ranging from $88 \%-95 \%$ and $95 \%-100 \%$, respectively [63].
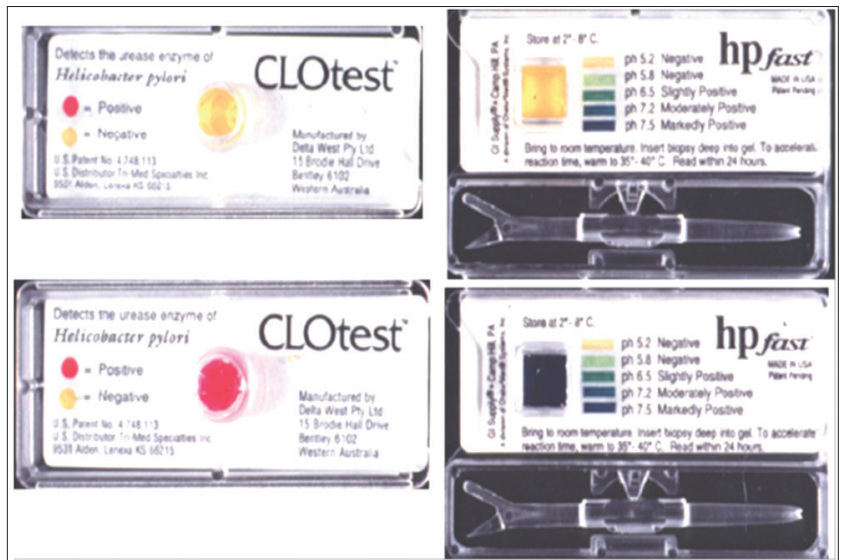

Fig. 6: Positive and negative results of Campylobacter-like organism test (CLO) test for Helicobacter pylori. The urease of Helicobacter pylori hydrolyzes urea to release ammonia, which is detected colorimetrically [58]

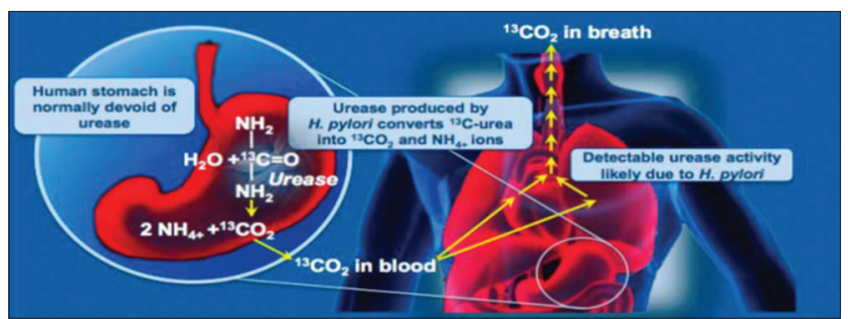

Fig. 7: The urea breath test detects urease activity, a marker of Helicobacter pylori infection, through the oral administration of carbon 13-labeled urea. If the stomach is infected with $\boldsymbol{H}$. pylori, its urease splits the carbon 13-labeled urea to produce ammonia and carbon 13-labeled $\mathrm{CO}_{2}$, which is expired in the breath [64] 
Recent studies have shown that 13 -labeled UBT $\left({ }^{13} \mathrm{C}\right.$-UBT) is a most reliable test for detection of $H$. pylori infection due to rapid, simple, innocuous, easy to repeat, reproducible, highly accurate, and economical manner [7]. Researchers have proved that this test is regarded as the gold standard, highest sensitivity and specificity ( $>95 \%)$, inexpensive, and convenient [64]. It was reported that the American College of Gastroenterology authenticated the carbon ${ }^{13} \mathrm{C}$-UBT as the most consistent test to confirm H. pylori eradication (Fig. 7) [65].

\section{Stool antigen non-invasive test}

At present, studies have shown that this test is obtainable and suitable for small children, as well as this test is cost-effective and need to less apparatus than UBT [61]. It has been reported that this test can be performed mostly in routine laboratories and also used to provide after the end of $H$. pylori infection treatment [45].

\section{CONCLUSION}

H. pylori infection is one of the global problems which are more affected in developing countries than in developed countries, and major risk factors for gastric cancer and PU. Different methods are used to detect H. pylori infection such as non-invasive or invasive test. ${ }^{13} \mathrm{C}$-UBT is more effective than other tests.

\section{REFERENCES}

1. Kirubakaran R, Ching YO, Kim PS, Nur AI. Prevalence of Helicobacter pylori infections among patients referred for endoscopy at hospital Sultan Abdul Halim. Asian Pac J Trop Dis 2016;6:358-60.

2. Osman HA, Hasan H, Suppian R, Hamzah NA, Sharif SE, Majid NM, et al. The characteristics of Helicobacter pylori infection and clinical outcomes of patient with upper gastrointestinal bleeding admitted at hospital Universiti Sains Malaysia. W App Sci J 2014;32:747-51.

3. Tunca A, Türkay C, Tekin O, Kargili A, Erbayrak M. Is Helicobacter pylori infection a risk factor for migraine? A case-control study. Acta Neurol Belg 2004;104:161-4.

4. Vannarath S, Vilaichone RK, Rasachak B, Mairiang P, Yamaoka Y, Mahachai V, et al. Antibiotic resistant pattern of Helicobacter pylori infection based on molecular tests in Laos. Asian Pac J Cancer Prev 2016;17:285-7.

5. Mustafa M. Choice of antimicrobial drugs for the eradication of Helicobacter pylori infection. Biomedica 2012;28:176-81.

6. Chak E, Rutherford GW, Steinmaus C. The role of breast-feeding in the prevention of Helicobacter pylori infection: A systematic review. Clin Infect Dis 2009;48:430-7.

7. Rienzo TA, Angelo GD, Ojetti V, Campanale MC, Tortora A, Cesario V, et al. ${ }^{13} \mathrm{C}$-Urea breath test for the diagnosis of Helicobacter pylori infection. E Rev Med Pharm Sci 2013;17:51-8.

8. Yousif A, Farid IA, Al-Qamish J. Metronidazole resistance of Helicobacter pylori in Bahrain. Bahrain Med Bullet 1995;17-23.

9. Kanbay M, Kanbay A, Boyacioglu S. Helicobacter pylori infection as a possible risk factor for respiratory system disease: A review of the literature. Respir Med 2007;101:203-9.

10. Kao CY, Sheu BS, Wu JJ. Helicobacter pylori infection: An overview of bacterial virulence factors and pathogenesis. Biomed J 2016;39:14-23.

11. Safavi M, Sabourian R, Foroumadi A. Treatment of Helicobacter pylori infection: Current and future insights. World J Clin Cases 2016;4:5-19.

12. Zhao S, Lv Y, Zhang JB, Wang B, Lv GJ, Ma XJ, et al. Gastroretentive drug delivery systems for the treatment of Helicobacter pylori. World $\mathbf{J}$ Gastroenterol 2014;20:9321-9.

13. Tadege T, Mengistu Y, Desta K, Asrat D. Seroprevalence of Helicobacter pylori infection in and its relationship with $\mathrm{ABO}$ blood groups. Ethiop J Health Dev 2005;19:56-60.

14. Duck WM, Sobel J, Pruckler JM, Song Q, Swerdlow D, Friedman C, et al. Antimicrobial resistance incidence and risk factors among Helicobacter pylori-infected persons, United States. Emerg Infect Dis 2004:10:1088-94

15. Hsu SC, Lee CL, Tu TC, Wu CH. The effectiveness of sequential therapy for non-ulcer dyspepsia patients with $H$. pylori infection. J Intern Med Taiwan 2010;21:125-32.

16. Chang YC, Huang CY, Hwang LC, Chang CC. The Association between Helicobacter pylori infection and metabolic syndrome in a Taiwanese adult population. J Metabolic Synd 2017;6:2-6.

17. Módena JL, Acrani GO, Micas AF, Castro Md, Silveira WD, Módena JL, et al. Correlation between Helicobacter pylori infection, gastric diseases and life habits among patients treated at a university hospital in Southeast Brazil. Braz J Infect Dis 2007;11:89-95.

18. Kilmartin CM. Dental implications of Helicobacter pylori. J Can Dent Assoc 2002;68:489-93.

19. Mounika P. Helicobacter pylori infection and risk of lung cancer: A Meta-analysis. Lung Cancer Int 2013;2013:131869.

20. Eyvazi S, Hakemi-Vala M. A review article on Helicobacter pylori antibiotic resistance profile in Iran. Int J Trop Dis Heal 2015;10:1-12

21. Das R, Gehlot V,Mahant S, Das K, Most of the Helicobacter pylori isolates are resistant to levofloxacin in North India. Int J Pharm Pharm Sci 2016;8:454-6.

22. Caliskan R, Tokman HB, Erzin Y, Saribas S, Yuksel P, Bolek BK, et al. Antimicrobial resistance of Helicobacter pylori strains to five antibiotics, including levofloxacin, in Northwestern Turkey. Rev Soc Bras Med Trop 2015;48:278-84.

23. Boyanova L, Ilieva J, Gergova G, Davidkov L, Spassova Z, Kamburov V, et al. Numerous risk factors for Helicobacter pylori antibiotic resistance revealed by extended anamnesis: A Bulgarian study. J Med Microbio 2012;61:85-93.

24. Kouitcheu Mabeku LB, Eyoum Bille B, Tchouangueu TF, Nguepi E, Leundji H. Treatment of helicobacter pylori infected mice with Bryophyllum pinnatum, a medicinal plant with antioxidant and antimicrobial properties, reduces bacterial load. Pharm Biol 2017; 55:603-10.

25. Bago J, Pevec B, Tomić M, Marusić M, Bakula V, Bago P, et al. Secondline treatment for Helicobacter pylori infection based on moxifloxacin triple therapy: A randomized controlled trial. Wien Klin Wochenschr 2009;121:47-52.

26. Wang YK, Kuo FC, Liu CJ, Wu MC, Shih HY, Wang SS, et al. Diagnosis of Helicobacter pylori infection: Current options and developments. World J Gastroenterol 2015;21:11221-35.

27. Yang HR. Updates on the diagnosis of Helicobacter pylori infection in children: What are the differences between adults and children? Pediatr Gastroenterol Hepatol Nutr 2016;19:96-103.

28. Kikuchi S. Epidemiology of Helicobacter pylori and gastric cancer. Int Japan Gas Canc Associat 2005;5:6-15

29. Kusters JG, Vliet AH, Kuipers EJ. Pathogenesis of Helicobacter pylori infection. Clin Microb Rev 2006;19:449-90.

30. Bartnik W. Clinical aspects of Helicobacter pylori infection. Polskie Arch Medy Wewnęt 2008;118:7-8.

31. Takashi T, Emi M, Takaaki K, Jun U, Tetsuya T, Yuto K, et al. Prevalence of Helicobacter pylori infection measured with urinary antibody in an urban area of Japan, 2008-2010. N J Med Sci 2012;74:63-70.

32. Goodman KJ. Implications of helicobacter pylori infection for stomach cancer prevention. Cad Saude Publica 1997;13 Suppl 1:15-25.

33. Walencka M, Gonciarz W, Mnich E, Gajewski A, Stawerski P, KnapikDabrowicz A, et al. The microbiological, histological, immunological and molecular determinants of helicobacter pylori infection in guinea pigs as a convenient animal model to study pathogenicity of these bacteria and the infection dependent immune response of the host. Acta Biochim Pol 2015;62:697-706.

34. Manes G, Balzano A, Vaira D. Helicobacter pylori and pancreatic disease. J Pancreas 2003;4:111-6.

35. Abd-Elsalam S, Nawasany SE, Elkhalawany W, Awny S, Mansour L, Ali1 LB, et al. Development and in-vitro evaluation of amoxicillin microspheres. Ind J Med Res Pharm Sci 2016;3:13-6.

36. Lee YC, Chiang TH, Chou CK, Tu YK, Liao WC, Wu MS, et al. Association between Helicobacter pylori eradication and gastric cancer incidence: A Systematic review and meta-analysis. Gastroenterology 2016;150:1113-2400000

37. Zhang RG, Duan GC, Fan QT, Chen SY. Role of Helicobacter pylori infection in pathogenesis of gastric carcinoma. World J Gastrointest Pathophysiol 2016;7:97-107.

38. Ramesh R, Wang SL, Li J, Wang YX, Rao QW, Yang CQ. Helicobacter pylori infection: A recent approach to diagnosis and management. J Biomed 2017;2:45-56.

39. Graham DY. Helicobacter pylori update: Gastric cancer, reliable therapy, and possible benefits. Gastroenterology 2015;148:719-31000.

40. Butcher LD, den Hartog G, Ernst PB, Crowe SE. Oxidative stress resulting from Helicobacter pylori infection Contributes to gastric carcinogenesis. Cell Mol Gastroenterol Hepatol 2017;3:316-22.

41. Cover TL. Helicobacter pylori diversity and gastric cancer risk. MBio 2016; 7:e1869-15

42. Araújo-Filho I, Brandão-Neto J, Pinheiro LA, Azevedo IM, Freire FH, Medeiros AC, et al. Prevalence of Helicobacter pylori infection in advanced gastric carcinoma. Arq Gastroenterol 2006;43:288-92.

43. Wu MS, Jyh-Ming LJ, Lin JT, Lee YC, Wu CY. Helicobacter pylori 
infection in the elderly. Int J Gerontol 2008;2:145-53.

44. Kadhim G, Omar H, Ismail A. Risk factors associated with peptic ulcer disease. J Bioeng Biomed Sci 2015;5:1-4.

45. Papastergiou V, Georgopoulos SD, Karatapanis S. Treatment of Helicobacter pylori infection: Past, present and future. World J Gastrointest Pathophysiol 2014;5:392-9.

46. Kumar PR, Doddayya HH, Rajendra RS. Floating tablets for Helicobacter pylori induced peptic ulcer therapy: A research review on formulation studies, in vitro and in vivo evaluation. J Biomed Pharm Res 2012;1:39-52.

47. Mirzaei N, Poursina F, Moghim S, Rahimi E, Safaei HG. The mutation of the rdxA gene in metronidazole-resistant Helicobacter pylori clinical isolates. Adv Biomed Res 2014;3:90.

48. Martínez MJ, Henao RS, Lizarazo RJ. Antibiotic resistance of Helicobacter pylori in Latin America and the Caribbeanl. Rev Col Gastroenterol 2014;29:217-26.

49. Alfizah H, Norazah A, Hamizah R, Ramelah M. Resistotype of Helicobacter pylori isolates: The impact on eradication outcome. J Med Microb 2014;63:703-9.

50. Thung I, Aramin H, Vavinskaya V, Gupta S, Park JY, Crowe SE, et al. Review article: The global emergence of Helicobacter pylori antibiotic resistance. Aliment Pharmacol Ther 2016;43:514-33.

51. Piscitelli SC, Danziger LH, Rodvold KA. Clarithromycin and azithromycin: New macrolide antibiotics. Clin Pharm 1992;11:137-52.

52. Megraud F. Antibiotic resistance in Helicobacter pylori infection. $\mathrm{Br}$ Med Bull 1998;54:207-16.

53. Mégraud F. The challenge of Helicobacter pylori resistance to antibiotics: The comeback of bismuth-based quadruple therapy. Therap Adv Gastroenterol 2012;5:103-9.

54. Kato T, Yagi N, Kamada T, Shimbo T, Watanabe H, Ida K, et al. Diagnosis of Helicobacter pylori infection in gastric mucosa by endoscopic features: A multicenter prospective study. Dig Endosc
2013;25:508-18

55. Cho JH, Chang YW, Jang JY, Shim JJ, Lee CK, Dong SH, et al. Close observation of gastric mucosal pattern by standard endoscopy can predict Helicobacter pylori infection status. J Gastroenterol Hepatol 2013;28:279-84

56. Patel SK, Pratap CB, Jain AK, Gulati AK, Nath G. Diagnosis of Helicobacter pylori: What should be the gold standard? World J Gastroenterol 2014;20:12847-59.

57. Garza-González E, Perez-Perez GI, Maldonado-Garza HJ, BosquesPadilla FJ. A review of Helicobacter pylori diagnosis, treatment, and methods to detect eradication. World J Gastroenterol 2014;20:1438-49.

58. David YG, Miftahussurur M. Helicobacter pylori urease for diagnosis of Helicobacter pylori infection: A mini review. J Advanc Res 2018;13:51-7.

59. Obey Z, Hanafiah A. Epidemiology, diagnosis and rick factors of Helicobacter pylori infection in children. Euro Asian J Hepato Gastroenterol 2017;7:34-9.

60. Ashwini P, Sumana MN, Shilpa U, Mamatha P, Manasa P, Dhananjaya BL, et al. A review on Helicobacter pylori: Its biology, complications and management. Int J Pharm Pharm Sci 2015;7:14-20.

61. Vianna JS, Ramis IB, Ramos DF, Groll AV, Silva PE. Drug resistance in Helicobacter pylori. Arq Gastroenterol 2016;53:215-22.

62. Fashner J, Alfred C, Gitu M. Diagnosis and treatment of peptic ulcer disease and Helicobacter pylori infection. Am Fam Physician 2015;91:236-42.

63. Weiquanm DJ, Khor DC. Testing and treating Helicobacter pylori infection. Singapore Fam Physician 2017;43:52-4.

64. Kamboj AK, Cotter TG, Oxentenko AS. Helicobacter pylori: The past, present, and future in management. Mayo Clin Proc 2017;92:599-604.

65. Howden CW, Chey WD, Vakil NB. Clinical rationale for confirmation testing after treatment of Helicobacter pylori infection: Implications of rising antibiotic resistance. Gastroenterol Hepatol (N Y) 2014;10:1-9. 